\title{
Experiência sensível e sociabilidade no IPPMG: quando o cinema vai ao hospital
}

\author{
Sensory experience and sociability in IPPMG: when the film goes to \\ hospital
}

\section{La experiencia sensible y sociabilidad en IPPMG: cuando la película va al hospital}

\author{
Tatiane Mendes | tatunha@gmail.com \\ Universidade Federal do Estado do Rio de Janeiro. Rio de Janeiro, Brasil
}

\section{Resumo}

Este artigo toma como base o método cartográfico de Virginia Kastrup (2009) para analisar a experiência do cinema em atividades realizadas pelo projeto educacional Cinema para Aprender e Desaprender (Cinead) com as crianças internadas nas enfermarias do Instituto de Puericultura e Pediatria Martagão Gesteira (IPPMG). Associando a cartografia à revisão bibliográfica, intenciona-se observar e debater as práticas socioculturais que têm como cerne a fruição e a produção fílmica. Para tanto, admite-se que essas práticas se aproximam da experiência sensível - como Michel Maffesoli (1998) denominou os fatos sociais contemporâneos, feitos de empatia e sensibilidade - que atravessa o espaço do hospital. A questão norteadora do presente estudo é se as vivências com o cinema possibilitam a construção da sociabilidade entre os participantes do projeto e a ressignificação simbólica do espaço em um ambiente onde as relações são marcadas cotidianamente pela imprevisibilidade.

Palavras-chave: Experiência sensível; Sociabilidade; Cinema como assunto; IPPMG; Cinead.

\begin{abstract}
This article uses the cartographic method of Virginia Kastrup (2009) to analyze the cinema experience at activities realized by the educational project Cinema para Aprender e Desaprender - Cinead (Cinema for Learning and Unlearning - Cinead), which works with children hospitalized in the wards of the Instituto de Puericultura e Pediatria Martagão Gesteira - IPPMG (Institute of Pediatrics Martagão Gesteira - IPPMG). With the mapping method and the literature review, our intent is to observe and discuss the socio-cultural practices whose heart is the enjoyment and the filmic production. To carry them out, it is assumed that those practices are close to the sensory experience - like Michel Maffesoli (1998) called the contemporary social facts, whose empathy and sensitivity are fundamental aspects - found in that hospital. The main question of this study is whether the experiences with film allow the construction of sociability among the participants of the project and the symbolic redefinition of space in an environment where relationships are marked by unpredictability daily.
\end{abstract}

Keywords: Sensory experience; Sociability; Montion pictures as topic; IPPMG; Cinead. 


\section{Resumen}

Este artículo está basado en el método cartográfico de Virginia Kastrup (2009) para analizar la experiencia del cine en las actividades llevadas a cabo por el proyecto educativo Cinema para Aprender e Desaprender - Cinead (Cine para Aprender y Desaprender - Cinead), con los niños hospitalizados en las enfermerías del Instituto de Puericultura e Pediatria Martagão Gesteira - IPPMG (Instituto de Pediatría Martagão Gesteira - IPPMG). Asociaciando la cartografía y de la revisión de la literatura tiene la intención de observar las prácticas socioculturales cuyo núcleo es la fruición y la producción fílmica. Para hacer esto posible, se supone que las prácticas están cerca de la experiencia sensorial - como Michel Maffesoli (1998) denominó los hechos sociales contemporáneos que tienen la empatía y la sensibilidad como factores fundamentales - encontradas en aquel hospital. La pregunta principal de este estudio es si las experiencias con el cine permiten la construcción de la sociabilidad entre los participantes del proyecto y la redefinición simbólica del espacio en un ambiente donde las relaciones están marcadas cotidianamente por la imprevisibilidad.

Palabras clave: La experiencia sensorial; La sociabilidad; Cine como asunto; IPPMG; Cinead.

Contribuição dos autores: A autora é responsável por todas as etapas do artigo.

Declaração de conflito de interesses: Não há conflito de interesses.

Fontes de financiamentos: Não houve financiamento externo envolvido.

Agradecimento/Contribuiç̧̃es adicionais: Agradeço a oportunidade extremamente transformadora de colaborar com o projeto CINEAD.

Histórico do artigo: Submetido:15.ago.2015 | Aceito: 27.abr.2016 | Publicado: 30.jun.2016.

Licença CC BY-NC atribuição não comercial. Com essa licença é permitido acessar, baixar (download), copiar, imprimir, compartilhar, reutilizar e distribuir os artigos, desde que para uso não comercial e com a citação da fonte, conferindo os devidos créditos de autoria e menção à Reciis. Nesses casos, nenhuma permissão é necessária por parte dos autores ou dos editores. 


\section{Introdução}

Em um ambiente hospitalar cercado pela busca incessante de conservação da vida e onde pessoas e tecnologias se revezam num esforço sem fim em prol dos pacientes que ali estão, qual a importância do sensível e da estética em face de tantas provações? Seria mero entretenimento, fuga inevitável da realidade ou experiência transformadora? Qual o lugar da comunicação nesse cenário? Estas são algumas das questões que o presente artigo pretende abordar. Para isso, com o olhar da comunicação, procurase analisar o projeto Cinema e Hospital, realizado desde 2011 no Instituto de Puericultura e Pediatria Martagão Gesteira (IPPMG). Sob o comando da equipe do Cinema para Aprender e Desaprender, o Cinead, a iniciativa Cinema e Hospital visa construir a experiência do cinema para crianças internadas no IPPMG, tanto por meio da exibição e produção de filmes, como através de atividades que tenham como cerne a linguagem cinematográfica.

O Cineadi é uma ação do Laboratório de Educação, Cinema e Audiovisual da Faculdade de Educação da UFRJ e promove projetos que tenham como cerne a relação entre educação, saúde e cinema. O projeto piloto foi concebido no Colégio de Aplicação da UFRJ em 2008 e, em 2012, foram criadas 13 escolas: sete salas em escolas públicas, três em hospitais (IPPMG ${ }^{\mathrm{ii}}$, Hospital Universitário UFRJ, CRMM-CR ${ }^{\mathrm{iii}}$ ), uma em um centro cultural no Vidigal (CineZé), uma no Ines ${ }^{i v}$ e outra no Instituto Benjamin Constant. Para efeito deste artigo, uma vez que se tinha a intenção de observar as relações entre comunicação e saúde, o objeto de pesquisa escolhido foi a atividade do IPPMG. Até 2014, segundo relatório do Cinead'1 ${ }^{1}$ o programa contou com 34 sessões de cinema envolvendo 70 crianças.

Para tentar alcançar a magnitude do projeto foi necessário associar a metodologia de revisão bibliográfica à pesquisa de campo, e utilizar o método cartográfico. Por tratar-se de experiência ainda em curso, o presente trabalho não pretende traçar um cenário final do objeto, mas promover o diálogo entre o arcabouço teórico proveniente da pesquisa bibliográfica realizada e as vivências com o corpus de pesquisa assim como iluminar os próximos passos da pesquisa de campo, realizada semanalmente nas enfermarias do hospital utilizando o método participante. Logo, a entrada na enfermaria acompanha o que Kastrup 4 observara como rastreio do campo, ou a busca de metas em um cenário móvel. Dadas as condições de uma enfermaria hospitalar, sempre em constante transformação, tal conceito não poderia ser mais exato. Contudo, há uma pré-condição singular para uma pesquisa como essa: ajustar o olhar para que o sensível seja o elemento direcionador.

Mas o que seria afinal a razão sensível? A opção de tomar como referencial teórico-metodológico a razão sensível - conceito-chave de Michel Maffesoli ${ }^{2-}$, para fundamentar as experiências observadas no IPPMG, obedece ao fato de que, para o autor, ela seria da ordem do afeto, ou uma alavanca metodológica que pode servir à reflexão epistemológica. É assim "plenamente operatória para explicar os múltiplos fenômenos sociais, que, sem isso, permaneceriam totalmente incompreensíveis”". Seriam o imaginário e as interações humanas pautadas no afeto os lugares de onde observar e compreender os fenômenos sociais. Este é o ponto de onde partir para interpretar o acontecimento em sua essência, permitindo chegar até o que o autor denomina o grund, a razão interna, que expressa uma cultura ou um conjunto de fenômenos sociais historicamente localizado. Toda análise social deve basear-se na busca do "fundamento, e não da simples causa, de todo ato, de toda representação, de todo fenômeno, a fim de perceber a sua razão interna, ainda que esta possa contrapor-se à razão funcional ou instrumental com a qual nos habituamos”².

\footnotetext{
i http://www.cinead.org Acesso em 03/08/2015.

ii http://www.ippmg.ufrj.br Acesso em 04/08/2014.

iii http://www.nepp-dh.ufrj.br/crmm/index.html. Acesso em 04/08/2014.

iv http://www.ines.gov.brl. Acesso em 04/08/2014.
} 
Tal perspectiva maffesoliana dialogará com o método cartográfico, na medida em que, em Kastrup³, a cartografia configura-se como uma desterritorialização do pesquisador, um deslocamento de sua posiçãocentral, aproximando-o de uma forma de fusão com o objeto pesquisado, da qual "[...] extraímos sentidos, atuamos em um plano expressivo que conota ao nosso ato de pesquisar um pouco daquilo de que são dotados os artistas: abrir-se para o sensível”3. De tal forma que, para observação dos acontecimentos sociais, é obrigatório compreender-se como parte de uma relação, uma rede de afetos e sentidos que se faz e se transforma diariamente, e em que observar e intervir se imbricam continuamente.

Em face das características singulares do projeto - o trabalho diário com crianças submetidas a um longo processo de internação e a tratamentos intensivos -, abrir-se para o sensível torna-se parte da práxis metodológica. Em um ambiente em que a dor e a morte são uma hipótese diária, a necessidade do afeto torna-se premente e estar em contato, olhar através do outro são condições básicas de trabalho. Nenhuma teoria solitariamente utilizada poderia servir para explicar o que significa um sorriso de compreensão mútua em um lugar onde a própria presença do outro, ante um corpo fragilizado, pode parecer invasiva. É preciso abrir-se para a vivência compartilhada e manter afastadas todas as ideias pré-concebidas. É fundamental, então, caminhar passo a passo mediante sinais do outro para que avancemos, seguindo pistas, referências que, como pensa Kastrup, "concorrem para a manutenção de uma atitude de abertura ao que vai se produzindo e de calibragem do caminhar no próprio percurso da pesquisa”3. Para tanto, o referencial teórico não pode servir como pré-condição ou recorte prévio. Ao contrário. Cada conceito deve ser incessantemente testado em confronto com a realidade observada durante a pesquisa de campo. Por tratar-se de pesquisa em curso, não há intenção de fornecer um manancial de resultados fechados, mas de traçar um quadro das experiências vivenciadas até então e confrontá-las com a pesquisa bibliográfica, produzindo reflexões necessárias sobre o objeto pesquisado.

Uma última ressalva se faz indispensável: o uso do termo cinema, apesar do reconhecimento de que as práticas com a linguagem fílmica se encontram atravessadas por novas formas tecnológicas, configurandose próximas do audiovisual. Usa-se aqui o modo audiovisual para a referência não só ao produto cinema, mas também aos meios que concatenam linguagens de som e imagem e se hibridizam nos projetores e nas novas tecnologias. Há uma aproximação do pensamento de Philipe Dubois ${ }^{4}$. Observando a diferença entre os processos fílmicos tradicionais, em película e as tecnologias de projeção digitais, Dubois considera que o cinema sempre vai ser sempre referência e essência das produções audiovisuais. Logo, o uso da terminologia de cinema é uma escolha retórica, não metodológica ou teórica, uma vez que há autores que utilizam o termo "cinema" em um cenário onde a película já foi substituída, em grande parte, pelos meios digitais. Reconhecendo que existem incorporações tecnológicas inescapáveis no cinema e constantes debates sobre a preponderância deste ou daquele termo, admite-se no presente trabalho o uso do cinema para referenciar as práticas do projeto analisado.

\section{Experiência sensível e sociabilidade: percurso teórico}

O referencial teórico no qual se baseia o estudo em pauta firma-se em alguns campos teóricos. Inicialmente, recorre às formas sociológicas da interação para pensar conceitos como a sociabilidade, de Simmel" e à sociologia compreensiva maffesoliana como a do "lado de dentro"3, que entende um fluxo contínuo entre pensamento e mundo, de afetos recíprocos, e a experiência como uma ação plural. Por este viés, observar as interações no IPPMG é fazer-se também matéria a ser analisada, afetada; ou seja, buscar a essência de um fenômeno que ao pesquisador também afeta e define.

A experiência também será abordada sobre os seguintes aspectos: sob o viés sensível ${ }^{2}$, como potência transformadora, e do cinema como forma de experiência artística, de Alain Bergala ${ }^{6}$. Em sintonia com esses aspectos, é preciso olhar para a arte sob o aspecto relacional, partilhado. Corroborando a ideia da 
experiência compartilhada e sensível de Maffesoli³ $^{3}$, utilizam-se pressupostos de Jacques Rancière ${ }^{7}$ na partilha do sensível e de Nicolas Bourriaud, sobre a arte como lugar de produção de sociabilidade e "esfera das relações humanas". A arte, então, "por ser da mesma matéria de que são feitos os contatos sociais, ocupa um lugar singular na produção coletiva" ${ }^{9}$, e a cartografia, como algo que está além do indivíduo, é relacional por excelência.

Corrobora a percepção de Bourriaud, a ideia de partilha do sensível, como "a relação entre um conjunto comum partilhado" . Em um ambiente onde cada centímetro de espaço é reorganizado e ressignificado a todo o momento, a ideia de partilha torna-se ainda mais necessária, posto que é preciso compreender a necessidade de outro, seja ele paciente ou profissional de saúde, em suas tarefas cotidianas e fazer-se flexível, para que as práticas fílmicas possam ocorrer sem prejudicar as rotinas hospitalares. Para tanto, é fundamental postar-se do lado de dentro da experiência, com atenção e sensibilidade.

Uma vez que se tem a intenção de utilizar a sociologia "do lado de dentro"2, será necessário dialogar o método cartográfico de Virginia Kastrup ${ }^{3}$ com os pressupostos de Jesús Martin-Barbero ${ }^{9}$, para pensar a observação no IPPMG como mapas construídos entre o pesquisador e o pesquisado, em que as "mãos veem ao mesmo tempo em que tocam" 9 . Pode-se acrescentar também: as mãos olham e tocam na mesma medida em que são tocadas e modificadas a cada interação.

É sob o viés do contato que se parte para observar o cinema em sua perspectiva de território afetivo, que Andrea França denomina "mapa de pertencimento" ${ }^{10}$. Tal ideia abarca aspectos ao mesmo tempo sensíveis, culturais e comunicacionais. Assim, mapear a potência de sociabilidade e vinculações entre espaços e sujeitos é propor a redefinição de fronteiras simbólicas e fluxos comunicacionais que se redefinem a cada momento (posto que tanto os pacientes quanto os profissionais de saúde movem-se constantemente) e o controle total das ações relativas ao cinema é impossível. Frente a esse cenário, assume-se postura similar à de Bergala ${ }^{6}$, quando este observa que não é produtivo controlar os processos criativos nas práticas fílmicas, mas que é preciso primeiro sensibilizar participantes para a experiência estética do cinema, proporcionar o encontro, e só depois fornecer as estratégias e técnicas de produção. Para isso o cinema, deve ser visto mais como uma forma de arte do que de linguagem. O que de mais importante pode ser extraído do contato com o ato de criação através do cinema é a experiência. Logo, com Bergala tem-se a ideia de que o "cinema tem a vocação [...] de nos fazer compartilhar experiências que, sem ele, nos permaneceriam estranhas, nos dando

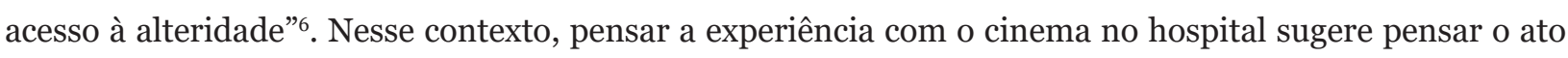
de experimentar encontros e fomentar a sensibilidade dos sujeitos que compartilham um mesmo espaço. Cabe relacionar aos sujeitos também o pesquisador, uma vez que na opção teórica e metodológica opta-se não pelo "saber sobre", mas pelo "saber com", passível de gerar pertencimento.

Por conseguinte, na característica coletiva acredita-se estar a maior potencialidade da experiência com o IPPMG. Socializar seria assim, como pensa Martin-Barbero, gerar vínculos na "trama das relações cotidianas que tecem os homens ao se juntarem"11. Também a forma de partilha do comum, seja ele estético ou politico se faz importante. Para vivenciar os aspectos mais significativos da experiência fílmica em sua totalidade no hospital é primordial, contudo, ter a coragem de entregar-se ao imponderável e imprevisível.

\section{Quando o cinema vai ao hospital}

Há experiências que determinam caminhos, tão intensamente e de modo tão devastador que é impossível continuar o mesmo após termos passado por elas. Nesse viés encontram-se definitivamente as práticas com as emoções e a arte. Após o contato com o projeto Cinema e Hospital é necessário acrescentar mais um elemento a essa lista: as práticas em ambientes onde a fragilidade humana se encontra a descoberto, caso das enfermarias infantis do IPPMG. Ao penetrar pela primeira vez nesse espaço, a primeira transformação ocorrida foi de que a visão do ato de comunicar prévia a essa experiência encontrava-se embaçada por 
formatos pré-concebidos, teorias diversas e alguma vivência prática, que levavam a crer no poder transformador da comunicação, mas definitivamente não eram suficientes para avaliar sua importância em situações extremas. Ao cruzar o limiar da realidade palpável das doenças graves, lentas e dolorosas é possível vislumbrar um definitivo lugar para o "entre", o relacional nesse espaço onde se encontram todas as demais pessoas que também dedicam a vida a minorar o sofrimento alheio. E é nesse lugar que se pensa a arte não como criação e fruição estética, mas como um caminho, entre tantos possíveis, até o outro, caminho que se faz apoiado nos processos comunicacionais. Mais do que isso, como uma ação, pautada no afeto e no sensível, que se faz comum, posto que, através da arte é possível se reconhecer naquele que está em um leito de hospital. Segundo Fernanda Omelczuk, coordenadora do projeto Cinema e Hospital "o cinema permite, ainda, outro exercício de alteridade, ao aproximar o outro no tempo e no espaço - de fato, conhecemos paisagens, culturas, costumes de outros países e épocas -, e ainda permite um melhor e mais profundo conhecimento de nós mesmos"'.

A experiência no IPPMG parece assim jogar por terra, desde o primeiro momento, tudo que se espera de uma prática a ser observada. Para começar, o espaço. A proposta do Cinead é a cada semana visitar uma enfermaria diferente, priorizando as salas onde há mais crianças. Ao longo do tempo, segundo relatórios desse projeto educacional, foi desenvolvido um diálogo com a equipe do hospital, que auxilia na escolha do local, informando onde há procedimentos que não podem ser interrompidos. Uma vez feita a escolha, é preciso ter a sensibilidade de perceber o momento de entrar e principalmente o momento de sair, posto que em alguns casos há interrupções necessárias, devido a tratamentos a serem realizados. Nesse cenário, em que as relações são fluidas, os laços não são fáceis de serem constituídos, uma vez que elas se modificam na mesma medida em que o espaço e seus ocupantes o fazem. Tal como Martin-Barbero ${ }^{9}$ define a cartografia, é necessário fazer recolocações contínuas do lugar, desterritorializações da perspectiva da qual se pensa e da própria experiência. Todas as leituras são continuamente deslocadas em mapeamentos que se rearranjam muitas vezes autonomamente.

A cada semana de visita, os pacientes são outros e diversas são as demandas; assim, dificilmente há continuidade nas atividades das quais se participou. Ao mesmo tempo, a rotina semanal impõe um cotidiano, proporcionando aos funcionários e parentes, que por ventura estiverem no local por mais de uma semana, a espera para tomar parte nas atividades. Há um roteiro básico nas práticas do Cinead que consiste em oferecer um cardápio de filmes às crianças e responsáveis, exibi-los e, a partir do filme projetado, propor brincadeiras em que as crianças possam descobrir a posição da câmera, ângulos e enquadramentos, ou a técnica utilizada. Em alguns dias, as crianças tomam a câmera nas mãos e realizam filmagens, sempre norteadas por algumas regras para a criação, vistas pela idealizadora do Cinead, professora Adriana Fresquet $^{12}$, como componentes fundamentais para fomentar a criatividade.

Na primeira visita realizada, no dia 17/07/2015, a enfermaria escolhida foi a de hematologia, com quatro crianças internadas. O cardápio de filmes foi oferecido a todas elas, mas algumas não quiseram tomar parte, preferindo aguardar de seus leitos o desenvolvimento das atividades. Mesmo assim, foi gratificante vê-las aos poucos moverem seus rostos em direção à "tela" para acompanhar o filme. Em primeiro lugar, é preciso aproximar a enfermaria minimamente da experiência cinematográfica, tal e qual as crianças têm em seu imaginário. Dessa forma, móveis são modificados, cortinas são fechadas e as luzes, inevitavelmente, apagadas. O filme exibido era uma animação e, logo depois, foram realizadas atividades para que os alunos descobrissem a posição da câmera utilizando eles mesmos uma câmera portátil trazida pela equipe do Cinead. A primeira impressão é de que não só os pequenos pacientes divertem-se com os jogos, mas também acompanhantes e até mesmo alguns profissionais de saúde, como se a experiência do cinema, aos poucos, contaminasse o ambiente. Por alguns minutos, cada participante das oficinas parece esquecer o motivo que lhe mantém no hospital e interage com os demais pais e crianças internadas. 
$\mathrm{Na}$ segunda e terceira visitas, realizadas respectivamente em 24/07/2015 e 31/07/2015, a escolha recaiu na enfermaria $C$, porque era a que tinha mais crianças. Além dos filmes, foram realizadas atividades com jogos de sombras, criação de personagens de papel, thaumatrópio ${ }^{v}$ e produção de filmes com os personagens feitos. Em todas as atividades há participação efetiva das crianças; entretanto, a exibição e a criação de filmes parecem ser as que mais mobilizam adeptos. Ao ouvirem os primeiros sons do filme, os rostos buscam a tela e os semblantes demonstram concentração. Mesmo nos mais refratários ao diálogo, percebe-se que a imagem convoca os olhares e, em alguma medida, chega até seus leitos. Tal situação se repetiu nas duas primeiras visitas, mas na terceira ocorreu um fato curioso. Atendendo aos pedidos de um dos meninos, a equipe levou um sortimento de filmes de suspense de animação. Enquanto se procuravam os filmes escolhidos, perguntou-se a uma das crianças se queria ver o filme realizado por outro menino, internado na enfermaria ao lado. Diante da afirmativa, o filme (que retratava o cotidiano de um pequeno paciente no CTI) começou a ser exibido mas, logo na primeira cena, ouviu-se a reclamação de um dos pais, de que essa história eles já viam todos os dias, não precisava ser mostrada. Tal reação sugere que a atividade dos filmes para os pais assemelha-se a uma fuga da realidade, um momento de respiro diante do cotidiano interno no hospital. Já para as crianças, a ação de filmar parece ser libertadora, utilizando-se da experiência estética como modo de estar no mundo, instrumento de ligação de seus imaginários com o mundo exterior, dos quais estão separados. Há também a necessidade de contar suas histórias através dos filmes. Como exemplo, uma das crianças, segundo relato da equipe do Cinead, ante a reprovação dos pais de que filmasse sua rotina no hospital, teria dito: "Quero contar minha história".

Dessa forma, as interações com a equipe do Cinead, mediadas pelo cinema, tornam-se mais significativas por convocarem a experiência sensível, sugerirem mundos possíveis, para além dos muros do hospital, "gestar uma forma de olhar de novo para as próprias vidas, com olhos de sonho, resgatar o extraordinário no familiar" ${ }^{12}$. Na experiência dos filmes, as crianças parecem criar vínculos entre suas vidas dentro e fora do hospital, colocando um pouco de suas emoções e vivências para criarem suas narrativas e participarem das atividades. Também aos olhos do pesquisador é necessário colocar as próprias emoções em cada atividade, posto que, se não se oferecer sem reservas a ter contato com as crianças não é possível trazerlhes para dentro das práticas. Assim, um olhar mais espantado, temeroso ou mesmo distanciado ante as rotinas e eventos de uma enfermaria, parece afastar os pacientes das vivências propostas. É necessária uma negociação de espaços, pela qual a criança permita que se entre em seu espaço e em seu cotidiano, para que se possa interagir com ela, se assim o quiser. E que possa vir até a equipe participar da maneira que lhe for mais confortável. Esse é o caso do menino, já anteriormente citado, realizador do filme sobre seu cotidiano no CTI. Com oito anos de idade, é descrito por alguns profissionais de saúde como muitas vezes arredio. Contudo, em relação ao cinema, parece estar sempre à frente de nossas ações, apresentando inúmeras e diferentes propostas.

Basta dizer que, na quarta visita (07/08/2015), ao ver a equipe do Cinead chegar, começou a chamar seus integrantes. O menino já sabe dividir uma história em pedaços, pensar em cada etapa do roteiro e acrescentar elementos para dar mais emoção à narrativa. No dia da visita, ele quis fazer um filme. Com um papel na mão, explicou claramente o que queria: dois dinossauros, que travariam uma luta de vida contra morte. Levaram-no até a câmera. Ele pediu uma cadeira, das de diretor, com nome nas costas. Deram-lhe a cadeira. Então ele pediu a claquete e explicou, ante o espanto geral, que servia para cortar os filmes. O menino sentou-se, pediu que lhe ajustassem o tripé, colocou a câmera no ângulo que lhe pareceu correto e recomendou ao ator/professor do Cinead a forma como ele devia entrar. Ajustados os aparelhos, ensaiado o ator (o diretor deixou claro que não queria usar bonecos como personagens. Queria o uso de sombras

v Jogo inventado entre 1820 e 1825 por William Fitton. Consiste em duas imagens sobrepostas em dois círculos presos a um barbante que, quando movimentados, dão a sensação de que as imagens se fundem. 
projetadas pela luz em um biombo de tecido). E assim foi. Quando tudo estava pronto no set ele ergueu as mãos, bateu palmas e disse: “ação!”. Em poucos minutos foi gravada a primeira cena. Então o "diretor" se levantou, postou-se atrás do biombo para representar o segundo personagem e novamente comandou a claquete: "ação!".

Cena filmada, o diretor quis ver o resultado e gostou do que viu. Então, categoricamente, perguntou onde o filme iria passar. Quando disseram que poderia ser enviado para um festival que exibia filmes em praças, ele interrompeu imediatamente, reforçando que não queria que seu filme fosse exibido em uma praça, mas numa sala escura, como a de um cinema de verdade. Tais ações denotam uma familiaridade com a linguagem cinematográfica que refletem o que Muniz Sodré ${ }^{13}$ observa sobre o bios midiatizado ${ }^{\text {vi }}$, a forma como as narrativas imagéticas, midiáticas se imbricam aos modos de ver o mundo, permeando imaginários de crianças como esse menino, realizador do filme anteriormente descrito. Sob essa perspectiva, a ação cotidiana do cinema no hospital parece ser um forte componente de comunicação e vinculação entre os participantes, posto que traz no cerne elementos que remetem ao cotidiano exterior, com o qual os pacientes demonstram querer dialogar.

$\mathrm{Na}$ última visita, realizada no dia 14/08/2015, o componente de deslocamento necessário para o exercício da cartografia tornou-se experiência vivida. Foi necessário abrir mão de qualquer ideia préconcebida e tornar a prática fílmica algo fluido, imediatamente adaptando-a às necessidades e rotinas da enfermaria. Dessa vez, a atividade repetiu-se com o mesmo menino da semana anterior, porque era dia do seu aniversário. Contudo, de seu leito cercado por balões e brinquedos, ele não demonstrou o menor interesse em tomar parte das atividades. Ignorou a proposta de animação e outras atividades sugeridas. Além disso, a própria enfermaria estava em processo de ajuste, com a chegada de alguns pacientes novos que ainda aparentavam nervosismo e desconforto com a internação. Houve também mudança de leitos e, para completar, um dos bebês internados chorava incessantemente. Tudo levava a crer que seria um dia perdido. Afinal, a observação participante demanda que as crianças aceitem a presença da equipe. Tal ideia dialoga com a perspectiva de Bergala ${ }^{6}$ sobre os encontros no cinema como algo que não se pode obrigar. Não se pode forçar alguém a ser tocado pela experiência.

Contudo, após um bom período de silêncio, o menino aniversariante chamou a equipe e pediu um filme para comemorar o aniversário. As cortinas foram fechadas, o equipamento ligado e então começou a exibição. Como que por magia, dois dos bebês automaticamente pararam de chorar e passaram a prestar atenção e até interagir com o filme, criando um ambiente de compartilhamento e ressignificação do espaço onde estavam os pequenos pacientes. Tal constatação dialoga com a perspectiva de Bergala ${ }^{6}$ de que o mais importante que pode ser extraído do filme é a experiência, que ressignifica lugar e sujeitos inseridos nesse espaço comum. Na valorização do que é vivenciado há um elo, gerado pelos afetos, em que as imagens narradas e geradas através da experiência sensível poderiam ser traduzidas como pontes através das quais o sujeito se reconhece, existe enquanto ser coletivo e consegue alcançar o outro. Em um universo no qual os humores, instintos e sensibilidades se exacerbam, as imagens tornam-se mais e mais relevantes na construção do social e necessárias para pensar o bem comum, que se localiza aqui sob a forma do bemestar, fundamental em um tratamento intensivo de saúde. O lugar da vivência estética nessa promoção do bem-estar não parece se localizar somente nas cores e nos sons dos filmes, mas nas práticas realizadas, que proporcionam às crianças estenderem seus olhares para outras culturas e outros mundos, sejam internos ou externos.

Cabe reforçar a ideia de que o possível elemento crucial das práticas realizadas pelas crianças é o fato das experimentações com o Cinead serem coletivas, compartilhadas em um mesmo ambiente, mesmo que

vi Sodré depreende de Aristóteles o conceito de um quarto bios que, para o autor brasileiro, seria o bios midiático, no qual os valores morais seriam influenciados e, de alguma forma, ditados pela mídia. 
limitado por restrições de contato devido ao tratamento de algumas crianças. Não foi à toa que Balázs afirmou que a experiência cinematográfica é identificada como "meio de comunicação visual sem a mediação de almas envoltas em carne"14. Em tal meio, a potência de sociabilidade localiza-se no ato de estar juntos durante a experiência sensível como transformadora, não só porque se trata de uma vivência fílmica, mas porque é uma vivência fílmica realizada coletivamente em um ambiente compartilhado, onde será possível conectar sujeitos envolvidos em um mesmo cotidiano hospitalar e, quem sabe, colaborar em alguma medida para a promoção do bem-estar. A arte então seria o elemento potencializador de contatos e afetos.

Ainda segundo Balázs, se "olharmos para os rostos e gestos de cada um de nós, não apenas estaremos nos entendendo, como também apreendendo a sentir as emoções de cada um”"14. Para nós, essa ideia reforça a esperança de que o cinema permita que isso aconteça. Somente assim, com a compreensão das emoções e necessidades de cada pessoa envolvida nas enfermarias, é possível prosseguir no percurso de pesquisa e de vida. E é nesse lugar que a comunicação se torna o elo possível de identificação que aproxima os sujeitos para além da enfermidade. É na projeção de um filme diante de rostos infantis, na atividade lúdica, no sorriso da educadora que reside não somente o estar junto, mas o "ser junto".

\section{Considerações finais}

O trabalho aqui apresentado não intenciona definir um resultado, mas propor uma reflexão do lugar que ocupa a comunicação em um projeto singular. Uma vez que se trata de projeto e pesquisa em curso em um ambiente em intensas e diárias transformações, somente o tempo e o aprendizado constantes conseguirão delinear nuances mais específicas. Contudo, no embate diário entre os pressupostos da comunicação e a prática vivenciada nas enfermarias do IPPMG, muitas questões se fazem presentes e motivam este artigo. Outras mais virão e demandarão um constante exercício de reorganização de métodos. Sobressai, todavia, a percepção da vivência sensível que emerge das práticas do Cinead na enfermaria. Uma existência compartilhada que se estende para além dos pequenos pacientes envolvidos entre fios, tubos e químicas e vai até os profissionais de saúde envolvidos e os pais das crianças, devastados por enfermidades por vezes tão agressivas quanto seus tratamentos.

No momento da projeção, em instantes, alguns pares de olhos se voltam para a narrativa da história mostrada em uma cortina, tornando-se parte do filme. Por alguns momentos, durante a sua exibição, criase um território distinto da dor e dos medicamentos, que parece romper os muros do hospital e levar pais e filhos a outro lugar possível. Mais do que isso. No ato de propor uma experiência, há o diálogo, o contato com o outro, a mão que se estende, não para fazer de conta que a doença não existe, mas ao contrário, para propor que, apesar da doença, todos nós continuamos existindo. Mais do que compreender o outro, trata-se de acolhê-lo. Na pequena enfermaria cria-se um lócus da afetividade, um território feito do sensível e do comum, onde as experimentações se cruzam, e os imaginários se comunicam no espaço dos leitos.

O cinema, nesse caso, torna-se então o espaço entre a ressignificação do lugar entre todos que dividem aquela experiência. Uma vez que se partilha o sensível, a comunicação é a trama que enreda cada um, propondo nexos. Sua importância se dá na medida em que o sujeito se reconhece não só na dor do outro, mas no seu sonho, na sua emoção. Comunicar seria então dar um passo para minorar o sofrimento de quem enfrenta batalhas diárias, seja no combate a enfermidades como o câncer, seja sofrendo na própria pele seus efeitos devastadores. Além de "estar com", no ato de ir até o outro e propor uma experiência sensível, há um componente fundamental de afeto que pôe em pé de igualdade educadores, pesquisadores e pacientes. Já não há mais observadores e observados, mas sujeitos inseridos em um mesmo território sensível e irremediavelmente humano. 


\section{Referências}

1. Omelczuk FW, Fresquet A, Santi A. Educação, cinema e infância: um olhar sobre práticas de cinema em hospital universitário. Interface. 2015;19(53):387-94

2. Maffesoli M. Elogio da razão sensível. Rio de Janeiro: Vozes; 1998.

3. Kastrup V. Pistas do método da cartografia: pesquisa-intervenção e produção de subjetividade. Porto Alegre: Sulina; 2009.

4. Dubois P. Cinema, vídeo, Godard. São Paulo: Cosac Naify; 2004.

5. $\quad$ Simmel G. Questões fundamentais da sociologia. Rio de Janeiro: Zahar; 2006.

6. Bergala A. A hipótese-cinema: pequeno tratado de transmissão do cinema dentro e fora da escola. Rio de Janeiro: Booklink: UFRJ; 2008.

7. Rancière J. A partilha do sensível: estética e política. Costa Netto M, tradutora. São Paulo: EXO Experimental: Editora 34, 2005.

8. Bourriaud N. Estética relacional. São Paulo: Martins Fontes; 2009.

9. Martín-Barbero J. Ofício de cartógrafo: travessias latino-americanas da comunicação na cultura. Gonzáles F, tradutora. São Paulo: Edições Loyola; 2004.

10. Martins, AF. Cinema de terras e fronteiras. In: Mascarello F, organizador. História do cinema mundial. São Paulo: Papirus; 2006.

11. Martín-Barbero J. Dos meios às mediações: comunicação, cultura e hegemonia. Rio de Janeiro: UFRJ; 2012.

12. Fresquet AM. Cinema e educação: Reflexões e experiências com professores e estudantes dentro e fora da escola. Belo Horizonte: Autêntica; 2013. p.92-93.

13. Sodré M. Antropológica do espelho: uma teoria da comunicação linear e em rede. Petrópolis: Vozes; 2010.

14. Balázs, B. O homem visível. In: Xavier I, organizador. A experiência do cinema: antologia. Rio de Janeiro: Edições Graal: Embrafilmes, 1983. 